\title{
Implementação do sistema de produção integrada de pêssegos no Paraná
}

\author{
Ligia Sayko Kowata $\left({ }^{1 *}\right)$; Lilian Amorim $\left({ }^{2}\right)$; José Carlos Fachinello $\left({ }^{3}\right)$; Louise Larissa May-De Mio $\left({ }^{1}\right)$ \\ (') Universidade Federal do Paraná (UFPR), Departamento de Fitotecnia e Fitossanitarismo, Rua dos Funcionários, 1540, Juveve, \\ 80035-050 Curitiba (PR). \\ (2) Universidade de São Paulo, Escola Superior de Agricultura “Luiz de Queiroz”, Departamento de Fitotecnia, Caixa Postal 9 , \\ 13418-900 Piracicaba (SP). \\ (3) Universidade Federal de Pelotas, Faculdade de Agronomia Eliseu Maciel, Departamento de Fitotecnia, \\ Caixa Postal 354, 96001-970 Pelotas (RS). \\ (*) Autora correspondente: ligiaufpr@gmail.com
}

Recebido: 19/fev./2009; Aceito: 10/jul./2010.

\section{Resumo}

A situação da produção integrada (PI) de pêssegos no Paraná foi avaliada considerando a importância do acompanhamento técnico especializado, os pontos de estrangulamento na adoção da tecnologia e a classificação das áreas em conformidade para PI. As safras de 2005/2006 (sem acompanhamento PI) e de 2006/2007 (com acompanhamento PI) foram comparadas, considerando 20 produtores orientados mensalmente para atender os requisitos contidos nas normas técnicas de PI para pêssego. A incidência da ferrugem (Tranzschelia discolor) e a da podridão parda (Monilinia fructicola) na floração foram quantificadas nas safras de 2006/2007 e 2007/2008 como parâmetros biológicos para caracterizar a eficiência do manejo adotado. A conformidade das propriedades ao sistema PI foi avaliada na safra 2007/2008, aplicando o Módulo complementar APOIA-NovoRural-PI (APOIA-PI). O índice de conformidade de cada propriedade foi comparado ao mínimo para a classificação em PI $(0,7)$. As maiores inconformidades no uso do caderno de campo foram: identificação do responsável técnico, monitoramento de pragas e coleta de dados climáticos. O acompanhamento técnico aumentou em média 60\% a conformidade no uso do caderno de campo. A incidência de podridão parda aumentou na safra de 2007/2008 em algumas áreas, ocasionada pelo não atendimento das recomendações técnicas PI. O manejo inadequado da ferrugem causou incremento no inóculo do patógeno, favorecendo o desenvolvimento da epidemia nos pomares. O APOIA-PI classificou duas propriedades como conforme para boas práticas agrícolas (BPA) $(0,7 \leq$ índice de conformidade $\geq 0,4)$, duas como produção integrada (PI) $(\geq 0,7)$ e as demais estavam com índices de conformidade menores que 0,4.

Palavras-chave: rastreabilidade, Prunus persica, Tranzschelia discolor, Monilinia fructicola, conformidade, certificação.

\section{Adoption of integrated production of peach system in Paraná State}

\section{Abstract}

The success in the adoption of peach integrated production (IP) was evaluated in small orchards of the Paraná State. The importance of specific technical accompaniment; points of strangulating in adoption of technology and the classification of the areas to IP conformity were evaluated. The seasons 2005/2006 (without IP orientation) and 2006/2007 (with IP orientation) were compared considering 20 producers who were oriented monthly to attend the minimum requisites. The incidence of peach rust (Tranzschelia discolor) and of brown rot (Monilinia fructicola) in full bloom was evaluated in 2006/2007 and 2007/2008 seasons, as biological parameters to accompany the efficiency of system adoption. After the technical accompaniment in 2007/2008 season, the software APOIA-Novo Rural-PI (APOIA-PI) was applied to measure the conformity to IP in peach orchards. The conformity index of each orchard was compared to the minimum requisite to classify as IP (0.7). The major difficulties in register of field book were: pests monitoring; collect of climate data and the harvest evaluation. The technical accompaniment increased in 60\% the conformity in use of field book. In 2007/2008 season, the brown rot incidence increased in some areas, caused by not following IP recommendations. The inadequate management caused the increment in pathogen inoculum, promoting the disease development in peach orchards. The APOIA-PI classified two orchards as good agricultural practices (GAP) $(0.7 \leq$ conformity index $\geq 0.4)$, two as integrated production (IP) ( $\geq 0.7)$ and the other orchards had conformity index lower than 0.4 .

Key words: rastreability, Prunus persica, Tranzschelia discolor, Monilinia fructicola, conformity, certification. 


\section{INTRODUÇÃO}

A área de pessegueiro no Brasil é superior a 21 mil hectares, com produçáo em torno de $239 \mathrm{mil} \mathrm{t} \mathrm{ano}^{-1}$, sendo o maior produtor o Estado do Rio Grande do Sul, o qual produz aproximadamente $129 \mathrm{mil} \mathrm{t} \mathrm{ano}^{-1}$ (IвGE, 2008). A produçáo de pêssego no Paraná é representada por 1.299 propriedades, as quais produzem 16.873 toneladas em 1.526 hectares de pomares (IвGE, 2008).

A baixa produtividade do Paraná está relacionada com as propriedades pouco tecnificadas, onde se observa problemas na adubaçâo, tratos culturais e principalmente no manejo fitossanitário (FACHINELlo et al., 2009). As principais doenças nos pomares de pessegueiro são: a podridão parda (Monilinia fructicola) e a ferrugem (Tranzschelia discolor). A primeira ocasiona danos tanto no pomar, como durante a comercializaçáo (MAY-De Mio et al., 2004) e a segunda tem aumentado em importância nos últimos anos nos pomares, devido à falta de controle químico após a colheita, principalmente em propriedades com baixo nível tecnológico (CHAlliol et al., 2006). A adoção de sistemas com produtos diferenciados e certificados, como os da produção integrada (PI), é uma opção para aumentar o nível tecnológico nas propriedades, corrigir técnicas agronômicas empregadas equivocadamente e agregar valor ao produto.

A produção integrada (PI) é um sistema de produção que visa integrar técnicas como o monitoramento de pragas e doenças, a análise foliar e o controle biológico, com as diferentes áreas agronômicas, para obter produtos com qualidade, passíveis de rastreabilidade e oriundos de um processo produtivo.Para esse fim, foram priorizadas a redução do impacto ambiental e a melhoria na qualidade de vida das pessoas envolvidas na atividade (Tiвola et al., 2005). A produção integrada de pêssego (PIP) no Brasil iniciou-se no Rio Grande do Sul, em 1999 (Fachinello, 2001). No Paraná, o sistema teve início em 2002 com a validação das normas técnicas no Estado e a sensibilização dos produtores ao novo sistema (CHAlliol et al., 2006, May-De Mio et al, 2008).

Atualmente, os trabalhos realizados com a PI estão direcionados aos aspectos técnicos, como a diferença entre a intensidade de doenças entre os sistemas integrado e convencional (Challiol et al., 2006; MaY-De Mio et al., 2008), produtividade e economicidade (FACHINELlo et al., 2005). Poucos são os trabalhos referentes à conformidade da PI nas propriedades rurais e a aceitabilidade do sistema por parte dos produtores (Tibola et al., 2007; SAntos et al., 2008).

Ao longo do tempo, programas como o APOIA-NovoRural (APOIA) têm sido desenvolvidos para mensurar o impacto das atividades desenvolvidas nas áreas rurais e comparar sistemas de produção (Rodrigues e CAMPANHOLA, 2003). O APOIA conceitua-se como um sistema de avaliação ponderada de impacto ambiental de ativida- des, no qual são consideradas dimensôes de sustentabilidade (Rodrigues et al., 2003). Embora empregado em várias cadeias produtivas, não é específico para avaliar os sistemas de PI. Penteado Junior et al. (2009) propuseram um módulo complementar ao APOIA, chamado APOIANovoRural-PI, que contempla as diretrizes do marco legal da PI no Brasil (Andrigueto e Kososki, 2002) e todas as áreas temáticas (AT) contidas nas normas técnicas específicas para PI de pêssego (FACHinello et al., 2003).

Considerando a falta de informação sobre a situação das propriedades rurais contempladas no projeto de implementação da PI no Estado do Paraná, estas foram avaliadas quanto à conformidade ao sistema, de acordo com os requisitos observados no momento da certificação. Adicionalmente, foi observada a importância do acompanhamento técnico especializado (engenheiro agrônomo credenciado para assistência técnica da PI), os pontos de estrangulamento (dificuldades para a adoção do sistema) na adoção da tecnologia e a classificação das propriedades em conformidade ao sistema de PI.

\section{MATERIAL E MÉTODOS}

O trabalho foi realizado em 20 propriedades rurais, pertencentes ao projeto de implementação da produção integrada de pêssego (PIP) no Estado do Paraná, localizadas na regiáo metropolitana de Curitiba (PR), e distribuídas em cinco municípios: cinco em Campo Largo, quatro em Araucária, oito em Lapa, uma em Campo do Tenente, Quitandinha e Mandirituba. Os pomares de cada propriedade foram subdivididos em áreas homogêneas, constituídas pela mesma cultivar, ano de plantio, forma de manejo e empregados os mesmos tratos culturais e tratamentos fitossanitários. Estas áreas foram denominadas de unidades de avaliação (UA).

No início da safra de 2005/2006, os produtores rurais receberam os cadernos de campo, documento obrigatório da PI, o qual é vistoriado para o processo de certificação (FACHInello et al., 2003). No momento do recebimento dos cadernos de campo, os produtores receberam as orientaçốes sobre o preenchimento das planilhas do caderno de campo e como proceder ao monitoramento de pragas e doenças. Os produtores realizaram o preenchimento do caderno de campo sem acompanhamento de um engenheiro agrônomo credenciado para PIP. No fim da safra, os cadernos de campo foram recolhidos para avaliação conforme seu uso. Para a avaliaçấo da conformidade foram dadas notas para as planilhas preenchidas: 0 - sem preenchimento e/ou náo conforme; 0,5 - preenchimento incompleto e/ou parcialmente não conforme 1 - preenchimento completo e conforme. O critério da conformidade foi elaborado com base nas normas técnicas específicas da PIP (FACHINello et al., 2003) e no marco legal da PI (Andrigueto 
e Kososki, 2002), os mesmos documentos considerados na auditoria de certificação pelo auditor.

Após a análise de cada caderno de campo da safra de 2005/2006 foram confeccionados novos cadernos de campo específicos para as propriedades e entregues aos produtores no início da safra de 2006/2007. Durante esta safra foram realizadas 240 visitas, entre maio/2006 e abril/2007, as quais consistiram no acompanhamento técnico da PIP. Este acompanhamento técnico, além de fornecer informaçôes sobre as normas PIP, monitoramentos de pragas e doenças, realizou um levantamento sobre as condiçôes das propriedades rurais quanto à conformidade ao sistema PI, e também sobre a situação de cada produtor, com base em observaçóes e no caderno de campo.

$\mathrm{Na}$ primeira visita realizada, cada propriedade orientada para a PIP foi georreferenciada e os dados anotados no novo caderno de campo. Os produtores e as demais pessoas envolvidas no cultivo receberam treinamentos e foram orientados para realizar o monitoramento de pragas e doenças (preconizado pelo PIP) e preencher os campos das planilhas do referido caderno de campo. Para o monitoramento de pragas era recomendado monitorar a presença de mosca-das-frutas (Anastrepha fraterculus) e grapholita (Grapholita molesta) duas vezes por semana durante o período crítico de cada praga. Nas visitas subsequentes, o caderno foi analisado e novamente se discutiram os pontos com necessidade de esclarecimentos. $\mathrm{Na}$ terceira visita foi reconhecida a dificuldade dos produtores em realizar o monitoramento das doenças, e o responsável pelo acompanhamento técnico optou por fazê-lo.

As duas principais doenças do pessegueiro na regiāo: podridão parda (Monilinia fructicola) e ferrugem (Tranzschelia discolor) foram monitoradas nas safras de 2006/2007 e 2007/2008, como parâmetros biológicos para caracterizar a eficiência dos sistemas adotados em cada propriedade. Para o monitoramento das doenças foram marcadas 10 plantas em cada unidade de avaliação (UA), seguindo as recomendaçóes do Guia Ilustrado de Doenças de Rosáceas de Caroço (May-De Mio, 2007) e nas normas técnicas do PIP (FACHINello et al., 2003). Para o monitoramento da podridão parda, foram coletadas 50 flores/planta durante a plena floraçáo (aproximadamente $40 \%$ das flores abertas). Em estufa BOD, foram mantidas 25 flores/gerbox em câmara úmida a $25^{\circ} \mathrm{C}$ por três dias, e depois a $4{ }^{\circ} \mathrm{C}$ durante mais três dias, durante todo o período no escuro. Após esse procedimento, foi avaliada a incidência do sintoma típico da podridão parda nas flores (esporulaçáo na corola).

A incidência da ferrugem foi determinada em 20 folhas/planta em novembro e fevereiro. Considerou-se o mês de novembro para determinar a condiçáo inicial do pomar e a necessidade de controle químico, e fevereiro para verificar o efeito do manejo adotado. Adicionalmente, foi determinada a entrada do patógeno no pomar. Para ambas as doenças, quando detectado $1 \%$ de incidência era recomen- dado o programa de pulverização de fungicidas para evitar o avanço da epidemia (FACHINELlo et al., 2003).

No fim da safra de 2006/2007, para a análise da conformidade do caderno de campo, os documentos foram recolhidos para exame do conteúdo (com acompanhamento PI), utilizando o mesmo parâmetro de avaliação da safra anterior. Os dados da conformidade no uso do caderno de campo (expressos em notas) foram transformados em porcentagens e apresentados por planilhas do caderno de campo, as quais estão relacionadas com as áreas temáticas (AT), e propriedades rurais. Para a análise estatística utilizou-se o programa Statistica 6.0 (StATSoft, 2001), para comparação da conformidade ao sistema nas duas safras (com e sem acompanhamento técnico PI) utilizou-se $\mathrm{o}$ teste não-paramétrico intervalar Wilcoxon $(\mathrm{p}<0,01)$.

$\mathrm{Na}$ safra de 2007/2008, o módulo complementar APOIA-PI (Penteado Junior et al., 2009) foi aplicado nas propriedades rurais acompanhadas na safra anterior, para aferir o nível de adequação das propriedades à PI. O programa gera o nível de conformidade de cada área temática (AT) e um índice geral, ambos expressos graficamente e em valor. As áreas temáticas são em número de 15 e estão definidas no Marco Legal da produção integrada e contempladas nas normas técnicas da PIP, sendo classificadas em: Capacitação de Recursos Humanos; Organização de Produtores; Recursos Naturais; Material Propagativo; Implantaçáo de Pomares; Nutrição de Plantas; Manejo e Conservaçáo do Solo; Recursos Hídricos e Irrigação; Manejo da Parte Aérea; Proteção Integrada da Planta; Colheita e Pós-colheita; Análise de Resíduos; Processo de Empacotadoras; Sistema de Rastreabilidade e Cadernos de Campo e Assistência Técnica. As ATs abrangem aspectos técnicos a serem considerados durante o cultivo e são subdivididas em 39 critérios recomendados e obrigatórios, verificados nas auditorias de certificação ( $\mathrm{F}_{\mathrm{A}}$ CHINELlo et al., 2003). O índice geral de conformidade de cada propriedade foi comparado com o limite mínimo requerido pela PI $(0,7)$.

\section{RESULTADOS E DISCUSSÃO}

Os pomares de pessegueiro no Estado do Paraná, em sua maioria, são caracterizados por serem formados de diferentes cultivares de pêssegos para mesa com polpa branca e amarela. A área total de pomares implantados em cada propriedade variou de 0,42 a 16 ha, e 0,09 a 2 ha para área formada por apenas uma cultivar (Tabela 1). A área reduzida de pomar implantado com uma mesma cultivar reflete o perfil da maioria dos produtores de pêssego do Paraná. Estas são propriedades de pequeno porte com diversidade de espécies e cultivares, que não geram separadamente, o volume de comercializaçáo para o envio da produção aos locais de distribuição mais distantes, como a CEAGESP. A organização em cooperativas 
Tabela 1. Características das propriedades rurais da região metropolitana de Curitiba, PR ${ }^{(1)}$, Safra 2006/2007

\begin{tabular}{|c|c|c|c|c|c|c|c|}
\hline \multirow{2}{*}{ Prop. } & \multirow{2}{*}{$\begin{array}{c}\text { Altitude } \\
\text { m }\end{array}$} & \multicolumn{2}{|c|}{ Coordenadas geográficas } & \multirow{2}{*}{$\begin{array}{c}\text { Pomar } \\
\text { ha }\end{array}$} & \multirow{2}{*}{ UA } & \multirow{2}{*}{$\begin{array}{l}\text { Outras } \\
\text { culturas }\end{array}$} & \multirow{2}{*}{$\begin{array}{l}\text { Assistência. } \\
\text { técnica }\end{array}$} \\
\hline & & latitude & longitude & & & & \\
\hline 1 & 915 & $25^{\circ} 34^{\prime} 22^{\prime \prime}$ & $49^{\circ} 27^{\prime} 11^{\prime \prime}$ & 8,60 & 8 & Cereais* e fruteiras & EMATER \\
\hline 2 & 902 & $25^{\circ} 34^{\prime} 22^{\prime \prime}$ & $49^{\circ} 28^{\prime} 13^{\prime \prime}$ & 0,42 & 4 & Hortaliças & EMATER \\
\hline 3 & 905 & $25^{\circ} 34^{\prime} 10^{\prime \prime}$ & $49^{\circ} 26^{\prime} 10^{\prime \prime}$ & 0,78 & 8 & Cereais* & EMATER \\
\hline 4 & 898 & $25^{\circ} 33^{\prime} 39^{\prime \prime}$ & $49^{\circ} 32^{\prime} 15^{\prime \prime}$ & 0,78 & 4 & Cereais* & EMATER \\
\hline 5 & 929 & $25^{\circ} 51^{\prime} 4^{\prime \prime}$ & $49^{\circ} 55^{\prime} 45^{\prime \prime}$ & 2,00 & 7 & Cereais* & EMATER \\
\hline 6 & 921 & $25^{\circ} 50^{\prime} 40^{\prime \prime}$ & $49^{\circ} 54^{\prime} 30^{\prime \prime}$ & 5,80 & 10 & Cereais* & EMATER \\
\hline 7 & 895 & $25^{\circ} 50^{\prime} 21^{\prime \prime}$ & $49^{\circ} 55^{\prime} 54^{\prime \prime}$ & 2,10 & 5 & Cereais* & EMATER \\
\hline $8^{x}$ & 923 & $25^{\circ} 43^{\prime} 41^{\prime \prime}$ & $49^{\circ} 56^{\prime} 12^{\prime \prime}$ & 16,00 & 21 & Fruteiras & Própria ${ }^{(2)}$ \\
\hline 9 & 966 & $25^{\circ} 41^{\prime} 47^{\prime \prime}$ & $49^{\circ} 37^{\prime} 27^{\prime \prime}$ & 4,30 & 14 & Cereais* & EMATER \\
\hline 10 & 933 & $25^{\circ} 41^{\prime} 0,58^{\prime \prime}$ & $49^{\circ} 47^{\prime} 48^{\prime \prime}$ & 3,40 & 6 & Hortaliças & EMATER \\
\hline 11 & 920 & $25^{\circ} 42^{\prime} 27$ & $49^{\circ} 49^{\prime} 9^{\prime \prime}$ & 3,60 & 6 & Cereais* & EMATER \\
\hline 12 & 842 & $25^{\circ} 50^{\prime} 5^{\prime \prime}$ & $49^{\circ} 36^{\prime} 43^{\prime \prime}$ & 4,60 & 6 & Fruteiras & Contratada ${ }^{(4)}$ \\
\hline 13 & 844 & $25^{\circ} 59^{\prime} 0,1^{\prime \prime}$ & $49^{\circ} 39^{\prime} 48^{\prime \prime}$ & 14,70 & 8 & Fruteiras e cereais & Contratada \\
\hline $14^{x}$ & 929 & $25^{\circ} 46^{\prime} 16^{\prime \prime}$ & $49^{\circ} 15^{\prime} 54^{\prime \prime}$ & 11,40 & 25 & Fruteiras & Própria ${ }^{(2)}$ \\
\hline 15 & 955 & $25^{\circ} 23^{\prime} 51^{\prime \prime}$ & $49^{\circ} 33^{\prime} 5^{\prime \prime}$ & 1,50 & 6 & Fruteiras & EMATER \\
\hline 16 & 954 & $25^{\circ} 23^{\prime} 52^{\prime \prime}$ & $49^{\circ} 33^{\prime} 32^{\prime \prime}$ & 2,00 & 1 & Fruteiras & EMATER \\
\hline $17^{* *}$ & 998 & $25^{\circ} 23^{\prime} 46^{\prime \prime}$ & $49^{\circ} 32^{\prime} 41^{\prime \prime}$ & 0,80 & 2 & Fruteiras & EMATER \\
\hline $18^{* *}$ & 998 & $25^{\circ} 23^{\prime} 46^{\prime \prime}$ & $49^{\circ} 32^{\prime} 41^{\prime \prime}$ & 0,95 & 2 & Fruteiras & EMATER \\
\hline 19 & -- & -- & -- & 1,00 & 1 & Cereais* e fruteiras $^{*}$ & Contratada ${ }^{(3)}$ \\
\hline 20 & 896 & $25^{\circ} 59^{\prime} 3^{\prime \prime}$ & $49^{\circ} 28^{\prime} 9^{\prime \prime}$ & 1,30 & 3 & Fumo & EMATER \\
\hline
\end{tabular}

Prop.: Propriedade. UA: Número de Unidades de Avaliação (talhôes homogêneos). ( ${ }^{1}$ ) Municípios de Araucária (propriedade 1 a 4); Lapa (5 a 12); Campo do Tenente (13); Mandirituba (14); Campo Largo (15 a 19) e Quitandinha (20). ( $\left.{ }^{2}\right)$ Produtor com formaçáo agronômica e credenciado para produçáo integrada de pêssego (PIP). ( ${ }^{3}$ Agrônomo contratado e credenciado para PIP. $\left.{ }^{4}\right)$ Agrônomo de empresa de revenda sem curso PIP. ${ }^{\times}$Presença de abastecedor e empacotadora na propriedade. *Cereais: milho, feijão e soja.

** Mesma propriedade, mas com dois cadernos de campo. - Dados năo coletados.

ou associaçôes é uma alternativa para redução de custo na comercialização e contratar um responsável técnico. Outra estratégia é associação para a certificação, uma vez que as normas técnicas permitem o agrupamento de pequenos produtores com área de pomar plantado de até 25 ha, para pagamento em conjunto da certificação (Fachinello et al., 2003).

$\mathrm{Na}$ safra de 2006/2007, as planilhas referentes à 'caracterização dos talhôes' e 'aplicação de defensivos agrícolas' foram devidamente preenchidas, demonstrando o entendimento do produtor em dividir o pomar em áreas homogêneas (Tabela 2). A subdivisão do pomar em parcelas (talhōes), com as mesmas particularidades, é o primeiro passo para o planejamento de manejos específicos, considerando o estádio fenológico das plantas ou sua suscetibilidade a doenças e pragas.

As maiores inconformidades em relação ao caderno de campo estavam relacionadas com a 'identificação do produtor e responsável técnico' e 'o monitoramento da mosca-das-frutas' e da 'mariposa-oriental' (Tabela 2). A geada na safra de 2006/2007 acarretou o abandono de alguns pomares. No entanto, independentemente da quantidade produzida em cada ano, o monitoramento deve ser constante para criar um histórico da área e não prejudicar o manejo do pomar na safra seguinte. Neste contexto, TIBola et al. (2007) verificaram que o monitoramento das pragas-chave foi realizado conforme a recomendaçáo; porém, na maioria realizaram-se contagens esporádicas dos insetos capturados nas armadilhas e em alguns casos, os produtores efetuaram o monitoramento, mas não o utilizavam como parâmetro nas aplicaçôes de agrotóxicos.

A planilha 'identificação do produtor e responsável técnico' não foi adequadamente preenchida, devido à falta de um técnico fixo nas propriedades (Tabela 2). Por se tratar de um exercício de preenchimento, náo foi solicitado que o responsável fosse credenciado pela PIP. O responsável técnico credenciado pela PIP foi o engenheiro agrônomo que cursou o treinamento específico PIP. Diferente do monitoramento da grapholita e mosca-das-frutas, as planilhas de monitoramento de doenças e demais pragas foram preenchidas de modo adequado (Tabela 2 ), uma vez que este procedimento foi realizado pelo técnico PI. Tendo em vista a dificuldade do produtor em realizar estes monitoramentos, eles foram retirados das normas técnicas PIP, as planilhas foram reelaboradas e lançadas em 2008 (FACHINELLO et al., 2009).

A anotação da temperatura e precipitação pluvial foi considerada dificultosa pelos fruticultores por ser um registro diário durante toda a safra (Tabela 2). No entanto, o registro contínuo dentro da área de cada produtor é fundamental para correlação entre clima e doença, bem como para o acompanhamento histórico da ocorrência de geada, relacionando com as fases de desenvolvimento das plantas nas diferentes parcelas. Tiвola et al. (2008) também observaram resistência ao preenchimento do caderno de campo, e em alguns casos as aplicaçôes de defensivos agrícolas náo eram registradas corretamente, principalmente nos períodos de maior atividade do pomar. 
Tabela 2. Conformidade do uso do caderno de campo em produtores rurais em fase de implementação da produção integrada (PI) de pêssego na região metropolitana de Curitiba (PR), Safras 2005/2006 (sem acompanhamento técnico PI) e 2006/2007 (com acompanhamento técnico PI)

\begin{tabular}{|c|c|c|}
\hline \multirow{2}{*}{ Planilhas } & \multicolumn{2}{|c|}{ Preenchimento por safra (\%) } \\
\hline & $2005 / 2006$ & $2006 / 2007$ \\
\hline 1) Identificação do produtor e responsável técnico & 21,00 & 36,00 \\
\hline 2) Identificação da propriedade & 7,00 & 77,00 ** \\
\hline 3) Características das parcelas & 13,00 & $90,00 * *$ \\
\hline 4) Aplicações de agrotóxicos & 29,00 & $90,00 * *$ \\
\hline 5) Fertilização - adubação & 21,00 & $82,00 * *$ \\
\hline 6) Manejo do solo e das plantas invasoras & 8,00 & $85,00 * *$ \\
\hline 7) Tratos culturais - manejo & 8,00 & 85,00 ** \\
\hline 8) Tratos culturais - colheita & 13,00 & $72,00 * *$ \\
\hline 9) Monitoramento da mosca-das-frutas & 11,00 & 40,00 \\
\hline 10) Monitoramento da grapholita & 0,00 & $52,00 * *$ \\
\hline 11) Ocorrência de pragas no ciclo (1) & 3,00 & $77,00 * *$ \\
\hline 12) Monitoramento de doenças (2) & 0,00 & 85,00 ** \\
\hline 13) Monitoramento de doenças (3) & 5,00 & 90,00 ** \\
\hline 14) Controle dos equipamentos de pulverização & 8,00 & 82,00 ** \\
\hline 15) Registros climáticos & 8,00 & $67,00 * *$ \\
\hline
\end{tabular}

Para melhorar o preenchimento de caderno de campo são necessárias algumas mudanças, como o acompanhamento profissional com conhecimento nas normas da produção integrada de pêssego e a conscientização da importância de formar um histórico da área por parte do produtor.

Analisando as propriedades individualmente, a propriedade 1 necessitava de adequações nas construções de benfeitorias, pois não possuía um local para preparo de defensivos agrícolas, captava a água diretamente do rio e o preparo da calda de pulverização era próximo ao efluente, agravando o risco de contaminação da água. Para correçấo das inconformidades recomenda-se o acompanhamento profissional para escolha de local para construção de uma estrutura apropriada para o preparo de caldas (FAChinello et al., 2003). Tibola et al. (2008) observaram que $80 \%$ dos fruticultores acompanhados do Rio Grande do Sul captavam água diretamente do rio e nâo calibravam os pulverizadores. Além disso, foram utilizados os defensivos agrícolas náo liberados na grade PIP: deltametrina e fentiona (não seletivos), dimetoato (inseticida), oxitetraclina (bactericida) e benomil (fungicida, de uso proibido) (Tiвola et al., 2008).

Os grandes entraves na propriedade 2 foram: a) o pouco capital para investimento em benfeitorias e tratos culturais inadequados; b) inexperiência na produção de pêssego; c) falta de assistência técnica fixa e d) área reduzida para produção de pêssegos $(0,42 \mathrm{ha})$. A propriedade 3 , também com pouca área $(0,78 \mathrm{ha})$, teve melhor porcentagem de preenchimento do caderno de campo (90\%) quando comparado com a propriedade $2(70 \%)$ (Tabela 3). As propriedades cuja produção envolveu somente frutas possuíam manejo do pomar mais adequado (propriedades 8, 12, 14, 15, 16, 17 e 18) (Tabela 1). Naquelas em que a fruticultura não é a atividade principal, o manejo do pomar foi negligenciado.

Na propriedade 12, apesar do caderno de campo estar em branco (Tabela 3), o produtor manteve todas as atividades realizadas no pomar em uma caderneta própria. Alguns produtores preferem realizar anotaçóes em caderno próprio ou mesmo no computador, documentos estes não-apropriados para auditoria de certificação. Uma opçáo para os produtores, que preferem o registro no computador dos dados da safra, é a utilização de programas específicos que não possibilitem a adulteração das informaçóes. A empresa Checkplant desenvolveu um software que funciona como um caderno de campo online, o qual está em conformidade com normas da EurepGap e Tesco, além da PI (www.checkplant.com. br). Tiвola et al. (2008) utilizaram um software para preenchimento do caderno de campo, contudo a utilização deste aparato ainda não faz parte do cotidiano da maioria dos produtores paranaenses de pêssego. As propriedades 8 e 14 foram as de maior conformidade com as normas PI, com dois aspectos marcantes: presença de mão-de-obra capacitada em PIP e presença de abastecedor e empacotadora.

O nível de preenchimento do caderno de campo em todas as propriedades acompanhadas foi maior na safra de 2006/2007, com acompanhamento técnico. As principais deficiências para adequação às normas PI foram: falta de responsável técnico fixo com conhecimento nas normas PIP e ausências exigidas durante a certificação como abastecedor, empacotadora e banheiros femininos e masculinos próximos aos pomares. A construção destas 
Tabela 3. Preenchimento do caderno de campo (áreas temáticas) e incidência da ferrugem do pessegueiro (T. discolor) nas propriedades em fase de implementação da produção integrada (PI) de pêssego da região metropolitana de Curitiba (PR) ('), nas safras 2006/2007 e 2007/2008

\begin{tabular}{|c|c|c|c|c|c|c|c|}
\hline \multirow{4}{*}{ Prop. } & \multirow{3}{*}{ Preenchimento } & \multicolumn{3}{|c|}{ Safra 2006/07 } & \multicolumn{3}{|c|}{ Safra $2007 / 08$} \\
\hline & & \multicolumn{2}{|c|}{ I média } & \multirow{3}{*}{ Entrada ${ }^{(2)}$} & \multicolumn{2}{|c|}{ I média } & \multirow{3}{*}{ Entrada $^{(2)}$} \\
\hline & & nov. & fev. & & nov. & fev. & \\
\hline & $\%$ & \multicolumn{2}{|c|}{$\%$} & & \multicolumn{2}{|c|}{$\%$} & \\
\hline 1 & 86,67 & 0,50 & 33,00 & nov & 0,00 & 3,00 & jan \\
\hline 2 & 70,00 & -- & -- & -- & -- & -- & -- \\
\hline 3 & 90,00 & 0,50 & 36,67 & nov & 0,17 & 52,00 & nov \\
\hline 4 & 73,33 & 4,00 & 100,00 & nov & 8,50 & 48,00 & nov \\
\hline 5 & 76,67 & 0,00 & 38,13 & jan & 0,25 & 76,13 & nov \\
\hline 6 & 80,00 & 0,00 & 90,63 & dez & 0,63 & 4,13 & nov \\
\hline 7 & 73,33 & 15,13 & 98,88 & nov & 11,88 & 40,88 & nov \\
\hline 8 & 90,00 & 0,00 & 63,50 & dez & 3,10 & 48,60 & nov \\
\hline 9 & 86,67 & 0,67 & 36,83 & nov & 0,00 & 31,33 & fev \\
\hline 10 & 63,33 & 0,17 & 83,33 & nov & 0,17 & 61,33 & nov \\
\hline 11 & 80,00 & 0,50 & 65,00 & nov & 3,75 & 97,25 & nov \\
\hline 12 & 0,00 & 0,00 & 70,63 & jan & 0,00 & 22,75 & fev \\
\hline 13 & 53,33 & 0,00 & 63,17 & jan & 0,17 & 40,33 & nov \\
\hline 14 & 73,33 & 0,00 & 52,75 & jan & 0,00 & 37,33 & jan \\
\hline 15 & 86,67 & 0,00 & 18,67 & fev & 0,00 & 88,50 & jan \\
\hline 16 & 90,00 & 0,00 & 4,00 & fev & 0,00 & 0,50 & fev \\
\hline 17 & 76,67 & 0,00 & 12,50 & fev & 0,00 & 15,00 & fev \\
\hline 18 & 96,43 & 0,00 & 36,50 & fev & 0,00 & 2,25 & fev \\
\hline 19 & 85,71 & 0,00 & 15,00 & fev & 0,00 & 4,50 & fev \\
\hline 20 & 60,00 & 0,00 & 100,00 & dez & 0,01 & 100,00 & nov \\
\hline
\end{tabular}

Prop.: propriedades rurais. I.: incidência. nov.: novembro. fev.: fevereiro. (') Municípios de Araucária (propriedade 1 a 4); Lapa (5 a 12); Campo do Tenente (13); Mandirituba (14); Campo Largo (15 a 19) e Quitandinha (20). ( ${ }^{2}$ ) Mês do início dos sintomas da ferrugem nas plantas marcadas. - Dados não coletados.

benfeitorias garante condiçóes mínimas de higiene para os trabalhadores e produção de alimento seguro.

Quanto às doenças monitoradas, a infecção de Monilinia fructicola nas flores foi maior na safra de 2007/2008 do que na 2006/2007 (dados não apresentados). O nãoatendimento das recomendaçóes técnicas de controle em algumas propriedades aumentou o inóculo para a próxima safra. Souza et al. (2007) concluíram que para podridão parda é fundamental eliminar fontes de inóculo da doença, devido ao rápido progresso e à distribuição heterogênea da epidemia. Na safra de 2006/2007, a presença do patógeno na flor foi detectada em duas propriedades; dessas, somente na propriedade 5 houve mais de $1 \%$ de incidência. Na safra de 2007/2008, o inóculo de podridão parda nos pomares aumentou: o patógeno foi detectado em 14 talhōes distribuídos em 10 propriedades. A incidência acima de $1 \%$ foi verificada nas propriedades 7,11 , $12,13,14$ e 20, nesta última em três talhóes.

$\mathrm{Na}$ propriedade 20, após duas safras sem qualquer tipo de controle químico na cultivar Planalto, a incidência de podridáo parda nas flores foi extremamente alta $(4,4 \%)$. Na propriedade 11 , apesar dos tratamentos na floração com captana, iprodiona, tebuconazole e da précolheita até colheita com mancozebe e iprodiona, a permanência de frutos mumificados na safra de 2006/2007 contribuiu para aumentar a incidência de $M$. fructicola na floração $(2,8 \%)$ na safra de 2007/2008. O aumento de inóculo de doenças, devido aos tratamentos fitossanitários negligenciados para redução de custo, foi um problema constatado na propriedade 4. A infecção das flores acarreta sérias consequências, tanto em perdas na produção, como na formação dos cancros nos ramos, que servem de fonte de inóculo para frutos imaturos e maduros (BLEICHer e TANAKa, 1982).

Com relação ao monitoramento da ferrugem, a presença da doença em novembro (safra de 2006/2007) foi detectada em sete propriedades, mas em apenas duas a incidência foi maior que $1 \%$ (Tabela 3). Em fevereiro, da mesma safra, a incidência atingiu $100 \%$ das folhas amostradas nas propriedades 4 e 20 (Tabela 3 ). No primeiro monitoramento da safra de 2007/2008, em dez propriedades ocorreu a doença; quatro delas (propriedades 4, 7, 8 e 11) com incidência maior que $1 \%$ (Tabela 3 ). No segundo monitoramento, apenas duas propriedade tiveram altas porcentagens de ferrugem: propriedade $11(97,25 \%)$ e 20 (100\%) (Tabela 3). Ataques severos de ferrugem podem causar queda precoce das folhas e enfraquecimento na formação dos ramos produtores da próxima safra (BLEICHER e TANAKa, 1982). O controle da ferrugem propicia a manutenção das folhas na planta e subsequente aumento da concentração de carboidratos solúveis totais em ramos (Alves e May-De Mio, 2008). Na safra de 2007/2008, a incidência final foi menor em áreas onde a epidemia se iniciou em janeiro ou fevereiro (Tabela 3). 
Tabela 4. Conformidade à produção integrada (PI) de pêssego em diferentes áreas temáticas, segundo o programa Apoia-NovoRural-PI (Penteado Júnior, 2008) na região metropolitana de Curitiba, PR (1), safra 2007/2008

\begin{tabular}{|c|c|c|c|c|c|c|c|c|c|c|c|c|c|}
\hline \multirow{2}{*}{ Prop. } & \multicolumn{13}{|c|}{ Áreas temáticas } \\
\hline & 1 e 2 & 3 & 4 e 5 & 6 & 7 & 8 & 9 & 10 & 11 & 12 & 13 & 14 & 15 \\
\hline 1 & 0,09 & 0,04 & 0,21 & 0,15 & 0,36 & 1,00 & 0,68 & 0,12 & 0,14 & 0,26 & 0,01 & 0,15 & 0,01 \\
\hline 2 & 0,05 & 0,04 & 0,22 & 0,01 & 0,13 & 1,00 & 0,25 & 0,07 & 0,07 & 0,10 & 0,01 & 0,09 & 0,01 \\
\hline 3 & 0,04 & 0,03 & 0,21 & 0,05 & 0,18 & 1,00 & 0,41 & 0,09 & 0,12 & 0,17 & 0,01 & 0,13 & 0,01 \\
\hline 4 & 0,05 & 0,03 & 0,21 & 0,03 & 0,15 & 1,00 & 0,25 & 0,09 & 0,12 & 0,17 & 0,01 & 0,00 & 0,01 \\
\hline 5 & 0,11 & 0,09 & 0,43 & 0,40 & 0,46 & 1,00 & 0,71 & 0,18 & 0,16 & 0,48 & 0,01 & 0,15 & 0,01 \\
\hline 6 & 0,09 & 0,12 & 0,61 & 0,22 & 0,35 & 1,00 & 0,67 & 0,11 & 0,12 & 0,30 & 0,08 & 0,11 & 0,01 \\
\hline 7 & 0,05 & 0,04 & 0,22 & 0,07 & 0,18 & 1,00 & 0,38 & 0,06 & 0,12 & 0,10 & 0,01 & 0,11 & 0,01 \\
\hline 8 & 0,71 & 0,81 & 0,86 & 0,88 & 0,92 & 1,00 & 1,00 & 0,83 & 0,92 & 0,52 & 0,88 & 0,93 & 1,00 \\
\hline 9 & 0,09 & 0,12 & 0,61 & 0,41 & 0,48 & 1,00 & 0,63 & 0,10 & 0,13 & 0,17 & 0,01 & 0,13 & 0,01 \\
\hline 10 & 0,08 & 0,10 & 0,29 & 0,16 & 0,30 & 1,00 & 0,68 & 0,07 & 0,14 & 0,12 & 0,03 & 0,10 & 0,01 \\
\hline 11 & 0,05 & 0,04 & 0,21 & 0,04 & 0,20 & 1,00 & 0,45 & 0,11 & 0,12 & 0,12 & 0,01 & 0,00 & 0,01 \\
\hline 12 & 0,20 & 0,29 & 0,50 & 0,35 & 0,38 & 1,00 & 0,71 & 0,38 & 0,29 & 0,30 & 0,08 & 0,12 & 1,00 \\
\hline 13 & 0,28 & 0,28 & 0,59 & 0,49 & 0,48 & 1,00 & 0,68 & 0,20 & 0,55 & 0,30 & 0,23 & 0,28 & 1,00 \\
\hline 14 & 0,70 & 0,76 & 0,76 & 0,88 & 0,75 & 1,00 & 1,00 & 0,98 & 0,92 & 1,00 & 0,88 & 0,93 & 1,00 \\
\hline 15 & 0,09 & 0,13 & 0,46 & 0,21 & 0,35 & 1,00 & 0,77 & 0,17 & 0,12 & 0,15 & 0,01 & 0,12 & 0,07 \\
\hline 16 & 0,10 & 0,13 & 0,61 & 0,20 & 0,50 & 1,00 & 0,77 & 0,14 & 0,12 & 0,19 & 0,01 & 0,21 & 0,01 \\
\hline 17 & 0,10 & 0,13 & 0,61 & 0,20 & 0,50 & 0,00 & 0,77 & 0,14 & 0,12 & 0,00 & 0,01 & 0,00 & 0,01 \\
\hline 18 & 0,08 & 0,10 & 0,27 & 0,16 & 0,30 & 1,00 & 0,65 & 0,11 & 0,12 & 0,17 & 0,01 & 0,13 & 0,01 \\
\hline 19 & 0,06 & 0,07 & 0,46 & 0,34 & 0,28 & 1,00 & 0,67 & 0,14 & 0,13 & 0,15 & 0,01 & 0,09 & 0,17 \\
\hline 20 & 0,04 & 0,03 & 0,21 & 0,04 & 0,17 & 1,00 & 0,28 & 0,09 & 0,09 & 0,09 & 0,01 & 0,08 & 0,01 \\
\hline
\end{tabular}

Prop.: propriedades rurais. ( $\left.{ }^{1}\right)$ Municípios de Araucária (propriedade 1 a 4); Lapa (5 a 12); Campo do Tenente (13); Mandirituba (14); Campo Largo (15 a 19) e Quitandinha (20). Áreas Temáticas: 1 e 2 (capacitaçâo e organizaçăo dos produtores); 3 (recursos naturais); 4 e 5 (material propagativo e época de plantio); 6 (nutriçăo de plantas); 7 (manejo do solo); 8 (irrigação); 9 (manejo da parte aérea); 10 (proteção integrada da cultura); 11 (colheita e pós-colheita); 12 (análise de resíduos); 13 (processos de empacotadoras/ industriais); 14 (sistema de rastreabilidade, cadernos de campo e de pós-colheita) e 15 (assistência técnica).

O índice de conformidade de cada área temática (AT) variou de 0,16 a 0,89 , com média de 0,32 (Tabela 4). A oscilação demonstra a heterogeneidade entre os produtores, $\mathrm{e}$ os maiores índices obtidos pertencem àqueles que acompanham os preceitos da PI. Apenas quatro das 20 propriedades acompanhadas tinham assistência técnica com capacitação técnica em PIP (propriedades 8, 12, 13 e 14) (Tabela 4).

Nas áreas estudadas foi verificado o emprego sem embasamento técnico e científico de técnicas como a adubação ou aplicações químicas. Tibola et al. (2007) constataram que nas propriedades de Santa Catarina e Rio Grande do Sul, a não-conformidade estava aliada à gradagem para incorporação de adubos e análise química do solo e de análise foliar sem as periodicidades recomendadas respectivamente a cada três anos e anualmente.

A não-conformidade pode ser minimizada com cursos ministrados por técnicos capacitados em PI e outros profissionais sobre técnicas culturais e manejos adequados para os pomares. A resistência em frequentar cursos de aperfeiçoamento pode ser um entrave para o sistema. Segundo Raschiatore et al. (2007), os produtores agropecuários brasileiros devem ser capacitados de acordo com as técnicas de manejo adequadas e que respeitem as normas de boas práticas.

$\mathrm{Na}$ análise realizada percebeu-se a dificuldade organizacional dos produtores em formar associaçóes ou se vincular a uma entidade para obter melhores opçóes de mercado, trocas de informaçôes e respaldo técnico.
Com a caracterização das propriedades, monitoramentos realizados e o resultado do APOIA-PI, as propriedades podem ser classificadas em: produção local (PL) (índices $\leq 0,4)$; boas práticas agrícolas (BPA) $(0,4$ $\leq$ índice $\geq 0,7)$ e produção integrada (PI) $(\geq 0,7)$. Das propriedades acompanhadas, 16 possuíam características de produçáo local (PL), duas (propriedade 12 e 13) de boas práticas agrícolas (BPA) e duas (propriedade $8 \mathrm{e}$ 14) de produção integrada (PI) (Tabela 4). Os avanços do sistema de produção integrada podem ser visualizados inclusive nas propriedades enquadradas como produçấo local, em que os produtores foram sensibilizados pelo módulo de avaliaçấo (APOIA-PI) e o sistema de produção (PI). Consequentemente, começaram a incorporar técnicas preconizadas pela PI na propriedade, como a cobertura verde, poda verde e monitoramento de pragas-chave. Para Penteado Júnior et al. (2008), a adoção do sistema de PI propicia aumento na realizaçấo de treinamentos e especialização em níveis básicos e técnicos, resultando em importante impacto positivo no estabelecimento.

Quando relacionados os índices de classificação da conformidade à PI (conforme, processo intermediário e não conforme) com fatores biológicos (principais doenças do pessegueiro), observou-se que a infecção de $M$. fructicola nas flores acima de 1\% (safra 2006/2007) foi detectada apenas em um talháo na propriedade 5 , classificada como não conforme às normas de PIP. 
Na safra de 2007/2008, a presença do patógeno nas flores acima do limite PI foi detectada nas propriedades 7 , 11,12 e 13,14 e 20. Dessas, as propriedades 7, 11 e 20 foram classificadas como náo conformes; 12 e 13 como em processo intermediário de PI, e 14 como conforme à PI. Nessa última propriedade, depois de tomadas todas as medidas de controle recomendadas pela PI para a podridão parda, a doença foi controlada na colheita e póscolheita, não tendo reflexos nos frutos, a infecção de $M$. fructicola detectada na floração.

O controle preconizado pela PIP para $M$. fructicola consiste em tratamentos nos períodos críticos da cultura (inchamento de gemas, floração e pré-colheita) considerando o inóculo e histórico da área e a utilização de produtos recomendados pela PIP (menos tóxicos e mais específicos) priorizando a rotação do modo de ação. Adicionalmente, também deve ser considerada a utilização de técnicas culturais, como retiradas de frutos mumificados do pomar, e o emprego de agentes de biocontrole já testados em trabalhos desenvolvidos pela PIP, como o fungo antagonista Thricotecium roseum (Moreira e May-De Mio, 2008) e produtos alternativos como os fosfitos (Moreira e May-De Mio, 2009).

No monitoramento de ferrugem realizado para determinar a condiçấo inicial do pomar (novembro), observou-se a presença da doença em sete propriedades (safra 2006/2007), sendo duas com incidência maior de $1 \%$ e classificadas como não conforme às normas PIP. Os primeiros sintomas da doença nas propriedades em conformidade à PI foram observados em dezembro e janeiro, respectivamente, nas propriedades 8 e 14 (Tabela 3). Na avaliação, em fevereiro, a incidência foi de $63,50 \%$ e $52,75 \%$ (Tabela 3). A entrada do patógeno foi constatada nas propriedades classificadas em BPA em janeiro (safra 2006/07). A incidência em fevereiro foi semelhante nas duas propriedades (70,63\% para propriedade 12 e 63,17\% para propriedade 13) (Tabela 3). Nas propriedades classificadas como não conformes, a entrada da ferrugem na área foi constatada entre novembro e fevereiro (safra de 2006/2007 e 2007/2008; nesta última com exceção da propriedade 1, onde a entrada do patógeno foi constatada em janeiro).

A incidência de ferrugem em fevereiro apresentou grande oscilação (4\% a 100\%), e 10 propriedades tiveram incidência maior que 50\% (Tabela 3). As porcentagens baixas de incidência de ferrugem em fevereiro em algumas propriedades $(1 ; 16 ; 17 ; 18$ e 19) devem-se aos pomares serem formados por cultivares menos suscetíveis à ferrugem, respectivamente 'Bruna', 'Reubnnel' (amexeira), 'Charme', 'Eldorado' e 'Delanona'. Barbosa et al. (1994) também observaram diferenças na suscetibilidade à ferrugem entre cultivares. As cultivares estudadas por BARBOSA et al. (1994) pertenciam a uma seleção pertencente ao germoplasma do Instituto Agronômico de Campinas, eram mais adaptadas a regiôes de clima mais quente (Estado de São Paulo), não fazendo parte, assim, as cultivares plantadas nas propriedades rurais acompanhadas pela PI (Paraná).
Na safra de 2007/2008, a presença da doença em novembro foi observada em 10 propriedades rurais; destas, quatro estavam com incidência de ferrugem acima de $1 \%$ (Tabela 3). As incidências máximas da doença foram menores na safra 2007/2008 do que na safra 2006/2007, e das 20 propriedades avaliadas, em seis havia incidência maior que $50 \%$ (Tabela 3 ).

A aplicação do APOIA-PI não visa exclusivamente quantificar o índice de conformidade de cada estabelecimento com a PI, mas, em adição a essa análise, demonstrar o que pode ser melhorado ou corrigido nesses locais - tendo o avaliador um papel importante na interpretação dos resultados e no repasse das informaçóes. $\mathrm{Na}$ maioria das propriedades a PI ainda está na fase inicial de implantação, mas, quando implementado, o sistema pode agregar muitas vantagens nas propriedades.

Considerando os dados monitorados e observados, das 20 propriedades acompanhadas pelo projeto de PIP no Estado do Paraná, apenas duas (propriedades 8 e 14) estavam aptas a serem submetidas ao processo de certificação PIP e outras duas (propriedades 12 e 13) necessitavam de adequação no período de quarentenas para pedir certificação na próxima safra.

\section{CONCLUSÃO}

O acompanhamento técnico especializado em produção integrada melhorou em média $60 \%$ a conformidade do uso do caderno de campo. Os principais pontos de estrangulamento observados para adoção da produção integrada foram: a) a falta de um técnico responsável fixo inteirado das normas da produção integrada; b) ausência de benfeitorias obrigatórias na produção integrada, como abastecedor e empacotadora; c) falta de treinamento dos produtores e funcionários. Das 20 propriedades analisadas, duas foram classificadas como conforme para produção integrada; duas foram enquadradas em boas práticas agrícolas (processo intermediário para PI) e 16 não estavam em conformidade com as normas.

\section{AGRADECIMENTOS}

Ao Conselho Nacional de Desenvolvimento Científico e Tecnológico - CNPq, pela concessão da bolsa de mestrado à primeira autora (Edital MCT 27/2007).

\section{REFERÊNCIAS}

ALVES, G.; MAY-DE MIO, L.L. Efeito da desfolha causada pela ferrugem na floração e produtividade do pessegueiro. Revista Brasileira de Fruticultura, v.30, p.907-912, 2008. 
ANDRIGUETO, J.R.; KOSOSKI, A.R. (Org.) Marco legal da produção integrada de frutas do Brasil. 1.ed. Brasília: MAPA/SARC, 2002. 60p.

BARBOSA, W.; CAMPO-DALL'ORTO, F.A.; OJIMA, M.; KALIL, G.P.C.; LOVATE, A.A.; RIBEIRO, I.J.A. Incidência de ferrugem em folhas de pessegueiro e nectarineira do germoplasma IAC. Scientia Agricola, v.51, p.90-93, 1994.

BLEICHER, J.; TANAKA, H. Doenças do pessegueiro no Estado de Santa Catarina. 2. ed. Florianópolis: Empresa Catarinense de Pesquisa Agropecuária S.A., 1982. 53p.

CHALLIOL, M.A.; MAY-DE MIO, L.L.; CUQUEL, F.L.; MONTEIRO, L.B.; SERRAT, B.M.; MOTTA, A.C.V.; RIBEIRO JÚNIOR, P.J. Elaboração de escala diagramática para furo de bala e avaliação de doenças foliares em dois sistemas de produção em pessegueiro. Revista Brasileira de Fruticultura, v.28, p.391-396, 2006.

FACHINELLO, J.C. Avanços com a produção integrada de pêssego. Informe Agropecuário, v.22, p.61-66, 2001.

FACHINELLO, J.C.; COUTINHO, E.F; MARONDIN, G.A.B.; BOTTON, M.; MAY-DE MIO, L.L. Normas técnicas e documentos de acompanhamento da produção integrada de pêssego. 1.ed. Pelotas: Universidade Federal de Pelotas. Faculdade de Agronomia Eliseu Maciel, 2003. 95p.

FACHINELLO, J.C.; TIBOLA, C.S.; PICOLOTTO, L.; ROSSI, A.; RUFATO, L. Produtividade e qualidade de pêssegos obtidos nos sistemas de Produção Integrada e Convencional. Revista Brasileira de Fruticultura, v.27, p.64-67, 2005.

FACHINELLO, J.C.; MAY-DE MIO, L.L.; RANGEL, A. Produção Integrada de pêssego. In: MINISTÉRIO DA AGRICULTURA E PECUÁRIA E ABASTECIMENTO E SECRETARIA DE DESENVOLVIMENTO AGROPECUÁRIO E COOPERATIVISMO. Produção Integrada no Brasil: agropecuária sustentável alimentos seguros. 1.ed. Brasília: MAPA/ACS, 2009. p. 779-810.

IBGE, Instituto Brasileiro de Geografia e Estatística. 2008. Disponível em:<http://www.sidra.ibge.gov.br/>

MAY-DE MIO, L.L.; GARRIDO, L.; BUENO, B. Doenças de fruteiras de caroço In: MONTEIRO, L.B.; MAY-DE MIO, L.L.; SERRAT, B.M.; CUQUEL, F.L. Fruteiras de caroço: uma visão ecológica. 1. ed. Curitiba: UFPR, 2004. p.169-222.

MAY-DE MIO, L.L. Guia ilustrado de doenças de rosáceas de caroço. 1.ed. Curitiba: FUPEF, 2007.35p.

MAY-DE MIO, L.L.; MOREIRA, L.M.; MONTEIRO, L.B.; JUSTINIANO, P. Infecção de Monilinia fructicola no Período da Floração e Incidência de Podridão Parda em Frutos de Pessegueiro em Dois Sistemas de Produçáo. Fitopatologia Brasileira, v.33, p.173-180, 2008.

MOREIRA, L.M.; MAY-DE MIO, L.L.; SANHUEZA, R.M.V. Fungos Antagonistas e efeito de produtos químicos no controle da podridão parda em pomar de pessegueiro. Summa Phytopathologica, v.34, p.272-276, 2008.
MOREIRA, L.M.; MAY-DE MIO, L.L. Controle da podridão parda do pessegueiro com fungicidas e fosfitos avaliados em pré e pós-colheita. Ciência e Agrotecnologia, v.33, p.405-411, 2009.

PENTEADO JUNIOR., J.F.; MAY-DE MIO, L.L.; RODRIGUES, G.S. Avaliação do impacto social no processo de implantação da produçáo integrada de pêssegos nos municípios de Araucária e Lapa Paraná: um estudo de caso. Revista Acadêmica de Ciências Agrárias e Ambientais, v.7, p.11-21, 2009.

PENTEADO JUNIOR, J.F.; MAY-DE MIO, L.L.; MONTEIRO, L.B.; GAYER NETO, W. Apropriação e análise de custo de implantação de pomar de pessegueiro. Scientia Agraria, v.9, p.117-122, 2008.

RASCHIATORE, R.A.; SOUZA, M.T.S.; PEREIRA, R.S. O sistema agrícola de produção integrada e o sistema de informação. Organizações Rurais \& Agroindustriais, v.9, p.389-401, 2007.

RODRIGUES, G.S.; CAMPANHOLA, C. Sistema integrado de avaliaçáo de impacto ambiental aplicado a atividades do Novo Rural. Pesquisa Agropecuária Brasileira, v.38, p.445-451, 2003.

RODRIGUES, G.S.; CAMPANHOLA, C.; VALARINI, P.J.; QUEIROZ, J.F.; FRIGHETTO, R.T.S.; RAMOS FILHO, L.O.; ISIS RODRIGUES, I.; BROMBAL, J.C.; TOLEDO, L.G. Avaliação de Impacto Ambiental de atividades em estabelecimentos familiares do Novo Rural. Embrapa meio Ambiente. Jaguariúna: Embrapa Meio Ambiente, 2003. 44p. (Boletim de Pesquisa e Desenvolvimento, 17)

SANTOS, J.C.F.; RAIJ, B.van.; LIMA, A.J.; JÚNIOR, P.C.A. Avaliação de conformidades de cafeicultores do cerrado mineiro sobre exigências da produção integrada de café. Coffee Science, v.3, p.7-18, 2008.

SOUZA, S. R.; MAY-DE MIO, L.L.; SERRAT, B.M.; CHALLIOL, M.A. Doenças foliares, cancro e número de frutos relacionados com a adubação nitrogenada em pessegueiro. Revista Brasileira de Fruticultura, v.29, p.260-264, 2007.

STATSOFT INC STATISTICA 6.0. Tulsa, 2001. Disponível em www.statsoft.com, 2001.

TIBOLA, C.S.; FACHINELLO, J.C.; GRUTZMACHER, A.D. Handling of pests and diseases in integrated and conventional production of peach. Revista Brasileira de Fruticultura, v.27, p.215218. 2005.

TIBOLA, C.S.; FACHINELLO, J.C.; ROMBALD, C.V.; PICOLOTTO, L.; KRÜGER, L. Análise da conformidade na adoção das normas de Produçáo Integrada de Pêssego. Ciência Rural, v.37, p.1149-1152, 2007.

TIBOLA, C.S.; FACHINELLO, J.C.; ROMBALDI, C.V.; NORA, L.; ROSSI, A. De.; RUFATO, L. Traceability of peaches from integrated production in south Brazil. Scientia Agricola, v.65, p.10-15, 2008.

VARELLA, M.D.; PLATIAU, A.F.B. A nova tendência mundial de segurança alimentar e o sistema de certificaçóes. In: LAGES, V.; BRAGA, C.; MORELLI, G. (Ed.). Territórios em movimento: cultura e identidade como estratégia de inserção competitiva. Brasília: Relume Dumará, 2004. p.201-218. 